\title{
Occurrence of anterior uveitis in patients with spondyloarthritis treated with tumor necrosis factor inhibitors: comparing the soluble receptor to monoclonal antibodies in a large observational cohort
}

Gisèle khoury ( $\sim$ g-khoury@chu-montpellier.fr )

Hopital Lapeyronie https://orcid.org/0000-0003-2766-9866

Jacques Morel

Hopital Lapeyronie

Bernard Combe

Hopital Lapeyronie

Cédric Lukas

Hopital Lapeyronie

Research article

Keywords: pondyloarthritis, psoriatic arthritis, uveitis, TNF inhibitors

Posted Date: February 17th, 2020

DOI: https://doi.org/10.21203/rs.2.23605/v1

License: @) (1) This work is licensed under a Creative Commons Attribution 4.0 International License. Read Full License

Version of Record: A version of this preprint was published at Arthritis Research \& Therapy on April 26th, 2020. See the published version at https://doi.org/10.1186/s13075-020-02187-y. 


\section{Abstract}

Background: The objective of this study was to compare in real life the occurrence of anterior uveitis in patients with spondyloarthritis (SpA), including psoriatic arthritis (PsA), treated with the soluble-receptor etanercept (ETA) or monoclonal antibodies (mAb).

Methods: This was an observational, retrolective study. Patients with SpA who were prescribed anti-TNF agents between 2000 and 2014 were included. The risk of uveitis was interpreted qualitatively (number of subjects with at least one uveitis) and quantitatively (number of uveitis flares for each individual). Models were adjusted for propensity score of receiving preferentially mAbs or ETA.

Results: 429 patients were included (302 with SpA and 127 with PsA); 203 received a Mab and 226 ETA as a first TNF-a inhibitor. Probability of uveitis occurring during the first year of treatment was lower with ETA than mAbs but not significantly (odds ratio 0.94 [95\% confidence interval $0.35 ; 2.54], p=0.90$, on qualitative analysis and relative risk 0.62 [0.26; 1.46], $p=0.27$, on quantitative analysis) after adjustment for the propensity score. The over-time risk of uveitis was numerically higher with ETA than mAbs, but the differences were not statistically significant.

Conclusion: In this observational study, the risk of uveitis in patients with SpA does not appear to be greater with ETA than mAbs treatment. The occurrence of uveitis in patients receiving an anti-TNF-a agent seems linked more to history of uveitis than the prescribed molecule.

\section{Background}

Acute anterior uveitis is the most frequent extra-articular manifestation in spondyloarthritis (SpA) and sometimes the first symptom leading to the diagnosis of the disease: $25-40 \%$ of SpA patients will experience at least one acute anterior uveitis episode during the disease $(1,2)$. Although uveitis occurring during $\mathrm{SpA}$ usually has good prognosis and responds to local anti-inflammatory treatments (3), it impairs the quality of life of patients and can, mostly when recurrent, result in visual sequelae (4-6).

The incidence of acute anterior uveitis in patients with ankylosing spondylitis was found significantly reduced with infliximab or etanercept (ETA) as compared with placebo (1). A review of 8 randomized trials showed a decrease in the incidence of uveitis in patients receiving ETA versus placebo (7). In patients receiving adalimumab, the reduction in incidence as compared with placebo was estimated at $51 \%$ (8). Golimumab has been found effective in uveitis resistant to local treatments, general first-line treatments, and in some cases, other TNF-a inhibitors (TNFi) (9). Data provided by the randomized study RAPID-AxSpa, evaluating uveitis in both ankylosing spondylitis (AS) and non-radiographic axial SpA, also showed a marked decrease in incidence of acute anterior uveitis with certolizumab versus placebo(10).

Data on ETA are more discordant. The study of the Swedish register of biologics in AS patients showed a significantly higher incidence of uveitis with ETA than infliximab or adalimumab. This applied to the recurrence of uveitis but also de novo uveitis. Furthermore, patients with a history of uveitis in the 2 years before the introduction of an TNFi showed an increase in incidence of uveitis during the first 2 years of treatment if ETA was used as the first-line TNFi, whereas the use of infliximab or adalimumab as first-line treatment decreased the incidence (11). Similarly, another study involving a US database of SpA patients receiving a first TNFi showed a 1.9-fold higher risk of uveitis in the first year with ETA as compared with adalimumab (12), with no significant difference between ETA and infliximab $(1,12)$. According to current recommendations, symptoms of SPA (axial, peripheral) as well as extra-articular manifestations must be considered when planning the therapeutic strategy (13).

The main objective of this study was to compare the occurrence of anterior uveitis with ETA and monoclonal antibody (mAb) treatment in patients with SpA during the first year of TNFi treatment in daily practice. Secondary objectives were to compare the with the first-line TNFi and for all therapeutic lines. 


\section{Methods}

\section{Study design and setting}

This observational retrolective study was conducted with a monocentric cohort in the department of rheumatology of the university hospital of Montpellier, France. The data were collected from the electronic medical records of adult patients in whom TNFi agents were initiated for axial or peripheral SpA, including psoriatic arthritis (PsA). Data were collected on diagnosis based on the modified Assessment of SpondyloArthritis international Society (ASAS)(14) or New York criteria (15) for SpA and Classification Criteria for Psoriatic Arthritis for PsA (16) and the date of diagnosis, comorbidities, general treatments and conventional synthetic disease-modifying anti-rheumatic drugs potentially associated with TNFi, the TNFi treatment used and the time elapsed since its introduction, the uveitis episodes that occurred during pre-treatment and during treatment periods, especially during the first year.

Patients with a short follow-up after the introduction of TNFi therapy ( $<2$ years) and/or significant time intervals when they were not seen (> 3 years) were considered at risk of missing data. They or their rheumatologist were contacted by phone to obtain information. Patients were not involved in the design, or conduct, or reporting, or dissemination plans of our research.

Outcome and main analyses: The main outcome was defined in two ways: first by taking into account the occurrence of at least one uveitis during the treatment, resulting in a binary variable for qualitative analyses, then by counting the number of uveitis flares during treatment, resulting in a continuous variable for quantitative analyses. Our analyses focused on 3 periods: 1) the first year of TNFi treatment for every patient (Fig. 1a), 2) the whole period when patients received their first TNFi (Fig. 1b), and 3) the period when patients were on a TNFi regardless of therapeutic line (Fig. 1c).

\section{Statistical analysis}

Baseline data are presented as number (\%) or mean (SD) and were compared by chi-square test or Student t test. To compare the occurrence of uveitis before and after treatment, MacNemar chi-square test for matched series (each patient being their own control) was used for qualitative analyses. For quantitative analyses, the incidence of uveitis before and during treatment was expressed as uveitis/patient-months (or uveitis/patient-years), and the two incidences were compared by matched Wilcoxon test.

Because patients were excluded from the previous analysis when the number of uveitis flares was unknown, a sensitivity analysis was considered: these patients were assigned a value of 1 for the total number of uveitis events before the introduction of treatment (hypothesis resulting in the most limited estimation of the benefit of the TNFi). The efficacy of ETA and mAbs was compared qualitatively by logistic regression and quantitatively with Poisson regression, estimating odds ratios (ORs) and relative risks (RRs), respectively, with 95\% confidence intervals (Cls). Mixed models were used for the analyses that included all therapeutic lines.

Because of the observational design of this study and the channeling bias (confounding by indication) related to the choice of TNFi according to the presence or absence of a known history of one or many uveitis flares, the statistical models used were adjusted for a propensity score. This propensity score aimed at balancing the distribution of confounding factors among baseline characteristics across the ETA- and mAb-treated groups, to approximate the effect of a randomization $(17,18)$. Propensity score analysis assigns to every patient a probability between 0 and 1 of receiving ETA as TNFi treatment, according to the patient's characteristics at the time of the therapeutic decision. The propensity score was defined by a logistic regression model, with the chosen treatment (ETA or $\mathrm{mAb}$ ) as the dependent variable and the baseline characteristics showing a potential statistical association on univariate analysis $(p<0.20)$ with the choice of TNFi or onset of at least one uveitis in the first year of treatment as independent variables.

\section{Results}

\section{Patient characteristics (Table 1)}


A total of 429 patients were included: 203 received a mAb and 226 ETA (supplementary figure S1). At baseline, extra-articular symptoms, especially inflammatory bowel disease, were less frequent with ETA than mAb treatment. Other baseline characteristics did not differ between the two groups. 
Table 1

Baseline characteristics

\begin{tabular}{|c|c|c|c|}
\hline & $\begin{array}{l}\text { Monoclonal } \\
\text { antibodies }\end{array}$ & $\begin{array}{l}\text { Soluble receptor } \\
\text { (etanercept) }\end{array}$ & Total \\
\hline Number of patients & $203 / 429(47.3)$ & $226 / 429(52.7)$ & $429 / 429$ \\
\hline SpA (excluding PsA) & 146/203(71.9) & $156 / 226(69.0)$ & $\begin{array}{l}302 / 429 \\
(70.4)\end{array}$ \\
\hline PsA & $57 / 203(28.1)$ & 70/226 (31.0) & $\begin{array}{l}127 / 429 \\
(29.6)\end{array}$ \\
\hline Men & $128 / 203(63.1)$ & $133 / 226(58.8)$ & $\begin{array}{l}261 / 429 \\
(60.8)\end{array}$ \\
\hline Age, years, mean (SD) & $42.4(12.3)$ & $44.0(12.9)$ & $43.2(12.4)$ \\
\hline $\begin{array}{l}\text { HLA B27 } \\
\text { MD }\end{array}$ & $\begin{array}{l}111 / 175(63.4) \\
28 / 203(13.8)\end{array}$ & $\begin{array}{l}119 / 182(65.3) \\
44 / 226(19.5)\end{array}$ & $\begin{array}{l}230 / 357 \\
(64.4) \\
72 / 429 \\
(16.8)\end{array}$ \\
\hline $\begin{array}{l}\text { Time between diagnosis and introduction of the first TNF } \\
\text { inhibitor, years, mean (SD) } \\
\text { MD }\end{array}$ & $\begin{array}{l}6.9(8.2) \\
8 / 203(3.9)\end{array}$ & $\begin{array}{l}7.6(8.7) \\
12 / 226(5.3)\end{array}$ & $\begin{array}{l}7.3(8.5) \\
20 / 429 \\
(4.7)\end{array}$ \\
\hline $\begin{array}{l}\text { History of extra-articular symptoms before treatment } \\
\text { MD }\end{array}$ & $\begin{array}{l}137 / 197(69.5)^{\star} \\
6 / 203(3.0)\end{array}$ & $\begin{array}{l}119 / 217(54.8)^{\star} \\
9 / 226(4.0)\end{array}$ & $\begin{array}{l}256 / 414 \\
(61.8) \\
15 / 429 \\
(3.5)\end{array}$ \\
\hline $\begin{array}{l}\text { Uveitis } \\
\text { MD }\end{array}$ & $\begin{array}{l}41 / 188(21.8) \\
15 / 203(7.4)\end{array}$ & $\begin{array}{l}33 / 214(15.4) \\
12 / 226(5.3)\end{array}$ & $\begin{array}{l}74 / 402 \\
(18.4) \\
27 / 429 \\
(6.3)\end{array}$ \\
\hline $\begin{array}{l}\text { Psoriasis } \\
\text { MD }\end{array}$ & $\begin{array}{l}72 / 188(38.3) \\
15 / 203(7.4)\end{array}$ & $\begin{array}{l}81 / 210(38.6) \\
16 / 226(7.1)\end{array}$ & $\begin{array}{l}153 / 398 \\
(38.4) \\
31 / 429 \\
(7.2)\end{array}$ \\
\hline IBD & $19 / 203(9.4)^{\star}$ & $2 / 226(0.9)^{\star}$ & $\begin{array}{l}21 / 429 \\
(4.9)\end{array}$ \\
\hline $\begin{array}{l}\text { csDMARD treatment } \\
\text { Patients with sDMARD } \\
\text { Patients without sDMARD } \\
\text { MD }\end{array}$ & $\begin{array}{l}54 / 130(41.5) \\
76 / 130(58.5) \\
73 / 203(36.0)\end{array}$ & $\begin{array}{l}56 / 151(37.1) \\
95 / 151(62.9) \\
75 / 226(33.2)\end{array}$ & $\begin{array}{l}110 / 281 \\
(39.1) \\
171 / 281 \\
(60.9) \\
148 / 429 \\
(34.5)\end{array}$ \\
\hline Methotrexate & 44/130 (33.6) & 44/151 (29.1) & $\begin{array}{l}88 / 281 \\
(31.3)\end{array}$ \\
\hline Leflunomide & $2 / 130(1.5)$ & 2/151 (1.3) & $\begin{array}{l}4 / 281 \\
(1.4)\end{array}$ \\
\hline Sulfasalazine & $8 / 130(6.2)$ & 10/151 (6.6) & $\begin{array}{l}18 / 281 \\
(6.4)\end{array}$ \\
\hline \multicolumn{4}{|l|}{ Data are $\mathrm{n}(\%)$ unless indicated. } \\
\hline \multicolumn{4}{|l|}{${ }^{*} p<0.05$} \\
\hline $\begin{array}{l}\text { MD: missing data, SD: standard deviation, IBD: inflammat } \\
\text { disease-modifying anti-rheumatic drug }\end{array}$ & el disease, PsA: $p$ & iatic arthritis; sDM & ynthetic \\
\hline
\end{tabular}




\section{Uveitis occurrence:}

Qualitative description

In total, $73(6.3 \%)$ patients had a history of uveitis, 27 during the year before TNFi start; 19 of 396 (4.4\%) patients with available data had at least one uveitis episode during the first year of treatment. With all TNFi lines, 52 (12.9\%) patients had at least one uveitis episode (Table 2).

Quantitative description

During the first year of TNFi treatment, 43 uveitis episodes were reported. With all TNFi lines, 170 uveitis episodes were reported; 117 occurred with the first TNFi agent (Table 2).

Table 2

Occurrence of uveitis during the different time intervals of the study

\begin{tabular}{|c|c|c|c|c|}
\hline & \multicolumn{2}{|c|}{$\begin{array}{l}\text { Patients with at least one uveitis } \\
\text { (qualitative analysis) }\end{array}$} & \multicolumn{2}{|c|}{$\begin{array}{l}\text { Total number of uveitis cases } \\
\text { (quantitative analysis) }\end{array}$} \\
\hline $\begin{array}{l}\text { Between diagnosis and start of the } \\
\text { first TNF inhibitor }\end{array}$ & 73 & & 117 & \\
\hline Last year before TNF inhibitor & 27 & & 28 & \\
\hline \multirow[t]{3}{*}{ First year of TNF inhibitor } & ETA & 9 & ETA & 15 \\
\hline & $\mathrm{mAb}$ & 10 & $\mathrm{mAb}$ & 28 \\
\hline & Total & 19 & Total & 43 \\
\hline \multirow[t]{3}{*}{ First TNF inhibitor } & ETA & 23 & ETA & 50 \\
\hline & $\mathrm{mAb}$ & 19 & $\mathrm{mAb}$ & 67 \\
\hline & Total & 42 & Total & 117 \\
\hline \multirow[t]{3}{*}{ All TNF inhibitor lines } & ETA & 48 & ETA & 62 \\
\hline & $\mathrm{mAb}$ & 31 & $\mathrm{mAb}$ & 108 \\
\hline & Total & 52 & Total & 170 \\
\hline
\end{tabular}

ETA, etanercept; mAb, monoclonal antibodies

\section{Uveitis occurrence before and during TNFi treatment}

We found no significant decrease in number of participants with at least one uveitis episode when comparing the incidence of uveitis between the year before starting treatment and the first year of the first-line TNFi $(p=0.17)(F i g .1 a$, Table 3). When comparing the incidence of uveitis over the previous year and after the TNFi start, the main analysis did not find any significant difference between the two groups (0.0066 uveitis/patient-months in the previous year and 0.011 uveitis/patientmonths in the first TNFi year, $p=0.80 ;$ Table 4). As well, the sensitivity analysis (number of uveitis episodes set to 1 ) did not reveal a significant difference between the two incidences $(p=0.69$; Table 4$)$.

We compared the incidence of uveitis with first-line TNFi treatment versus the incidence during the time between the diagnosis of SpA and the introduction of the first TNFi (Fig. 1c). The qualitative analysis showed a significant decrease in number of patients with at least one uveitis episode $(p=0.0002)$ (Table 3$)$. The quantitative analysis as well as the sensitivity analysis revealed no significant difference in pre-treatment and treatment incidences $(p=0.19$ and $p=0.16$, respectively) (Table 4).

Finally, we compared the incidence of uveitis between the total period under TNF treatment, considering all therapeutic lines, and between the date of diagnosis and introduction of the first TNFi (Fig. 1C). The qualitative analysis revealed a significant 
decrease in incidence under treatment $(p=0.049)$ (Table 3), whereas the quantitative analysis revealed a significant increase in incidence under treatment $(p=0.04$ for the main analysis and $p=0.03$ for the sensitivity analysis; Table 4$)$.

Table 3

Qualitative analysis of the occurrence of at least 1 uveitis before and during TNF inhibitor treatment in patients with SpA or

\begin{tabular}{|c|c|c|c|c|c|c|c|c|c|c|c|c|c|c|}
\hline \multicolumn{15}{|c|}{ PsA } \\
\hline & & \multicolumn{3}{|c|}{$\begin{array}{l}\text { Uveitis } \geq 1 \text { during } \\
\text { the first year of } \\
\text { TNF inhibitor }\end{array}$} & & & \multicolumn{3}{|c|}{$\begin{array}{l}\text { Uveitis } \geq 1 \text { during } \\
\text { the first TNF inhibitor }\end{array}$} & & & \multicolumn{3}{|c|}{$\begin{array}{l}\text { Uveitis } \geq 1 \text { during } \\
\text { all TNF inhibitor } \\
\text { lines }\end{array}$} \\
\hline & & Yes & No & $\mathrm{p}$ & & & Yes & No & $p$ & & & Yes & No & $\mathrm{p}$ \\
\hline \multirow{2}{*}{$\begin{array}{l}\text { Uveitis } \\
\geq 1 \text { in } \\
\text { the year } \\
\text { before } \\
\text { TNF } \\
\text { inhibitor }\end{array}$} & Yes & 10 & 17 & \multirow[t]{2}{*}{0.17} & \multirow{2}{*}{$\begin{array}{l}\text { Uveitis } \\
\geq 1 \\
\text { before } \\
\text { TNF } \\
\text { inhibitor }\end{array}$} & Yes & 25 & 48 & \multirow[t]{2}{*}{0.0002} & \multirow{2}{*}{$\begin{array}{l}\text { Uveitis } \\
\geq 1 \\
\text { before } \\
\text { TNF } \\
\text { inhibitor }\end{array}$} & Yes & 6 & 67 & \multirow[t]{2}{*}{0.049} \\
\hline & No & 9 & 325 & & & No & 17 & 311 & & & No & 46 & 282 & \\
\hline
\end{tabular}


Table 4

Quantitative analysis of the incidence of uveitis before and during TNF inhibitor treatment in patients with SpA or PsA Incidence in the last year before TNF inhibitor and during the first year of TNF inhibitor treatment

\begin{tabular}{|c|c|c|c|}
\hline & & $\begin{array}{l}\text { Main analysis } \\
\mathrm{n}=350\end{array}$ & $\begin{array}{l}\text { Sensitivity analysis } \\
\mathrm{n}=351\end{array}$ \\
\hline \multirow[t]{2}{*}{ In the last year before TNF inhibitor } & Uveitis/patient-months, mean (SD) & $0.0066(0.0333)$ & $0.0066(0.0333)$ \\
\hline & Uveitis/100 patient-years & 7.92 & 7.92 \\
\hline \multirow[t]{2}{*}{ In the first year of TNF inhibitor } & Uveitis/patient-months, mean (SD) & $0.011(0.080)$ & $0.011(0.080)$ \\
\hline & Uveitis/100 patient-years & 13.2 & 13.2 \\
\hline $\mathrm{p}$ value & & 0.80 & 0.69 \\
\hline \multicolumn{4}{|c|}{ Incidence before TNF inhibitor introduction and during first TNF inhibitor treatment } \\
\hline & & $\begin{array}{l}\text { Main analysis } \\
\mathrm{n}=334\end{array}$ & $\begin{array}{l}\text { Sensitivity analysis } \\
\mathrm{n}=337\end{array}$ \\
\hline \multirow[t]{2}{*}{ Before TNF inhibitor } & Uveitis/patient-months, mean (SD) & $0.0040(0.023)$ & $0.00420(0.023)$ \\
\hline & Uveitis/100 patient-years & 4.81 & 5.04 \\
\hline \multirow[t]{2}{*}{ With first TNF inhibitor } & Uveitis/patient-months (SD) & $0.0086(0.056)$ & $0.0086(0.056)$ \\
\hline & Uveitis/100 patient-years & 10.32 & 10.32 \\
\hline $\mathrm{p}$ value & & 0.19 & 0.16 \\
\hline \multicolumn{4}{|c|}{ Incidence before TNF inhibitor introduction and during all TNF inhibitor lines of treatment } \\
\hline & & $\begin{array}{l}\text { Main analysis } \\
\mathrm{n}=334\end{array}$ & $\begin{array}{l}\text { Sensitivity analysis } \\
\mathrm{n}=344\end{array}$ \\
\hline \multirow[t]{2}{*}{ Before TNF inhibitor } & Uveitis/patient-months, mean (SD) & $0.0040(0.023)$ & $0,0042(0.023)$ \\
\hline & Uveitis/100 patient-years & 4.81 & 5.04 \\
\hline \multirow[t]{2}{*}{ With all TNF inhibitor lines } & Uveitis/patient-months, mean (SD) & $0.0052(0.022)$ & $0.0057(0.023)$ \\
\hline & Uveitis/100 patient-years & 6.24 & 6.84 \\
\hline$p$ & & 0.04 & 0.03 \\
\hline
\end{tabular}

\section{Propensity score allocation}

The variables selected for the propensity score were: occurrence of at least one uveitis in the whole period preceding the introduction of the first TNFi, age, sex, history of inflammatory bowel disease, delay between the diagnosis date and introduction of the first TNFi, and diagnosis of rheumatism (PsA or SpA) (supplementary table S1). This score balanced the probability of being assigned ETA as the first-line TNFi in both groups of patients (Supplementary figure S2).

\section{Qualitative analysis comparing uveitis incidence with ETA versus mAbs}

The crude incidence of at least one uveitis episode within 1 year after starting the first TNFi was numerically lower for patients with ETA than mAbs but not significantly $(\mathrm{OR}=0.81[0.32,2.03], \mathrm{p}=0.65)$ and was still lower on adjustment for the propensity score but not significantly $(O R=0.94[0.35,2.54], p=0.90)($ Table 5$)$. 
During the first-line TNFi treatment (Fig. 1b), the probability of at least one uveitis episode was higher with ETA than mAbs but not significantly $(\mathrm{OR}=1.39[0.71,2.72], \mathrm{p}=0.3)$ and was higher on adjustment for the propensity score but still not significantly $(\mathrm{OR}=1.89[0.90,4.01, \mathrm{p}=0.09)($ Table 5$)$.

When considering all prescribed therapeutic lines of TNFi agents, the probability of at least one uveitis episode was numerically higher with ETA than mAbs but not significantly $(O R=1.57[0.71,3.46], p=0.27)$ and was further increased on adjustment for the propensity score but still not significantly $(\mathrm{OR}=1.98[0.90,4.37], \mathrm{p}=0.08)($ Table 5).

\section{Quantitative analysis comparing uveitis incidence with ETA versus mAbs}

On quantitative analysis, the risk of uveitis within 1 year after starting the first TNFi was lower with ETA than mAbs but not significantly $(R R=0.54[0.24 ; 1.24], p=0.15)$ and was still lower on adjustment for the propensity score but not significantly $(\mathrm{RR}=0.62[0.26,1.46])(\mathrm{p}=0.27)($ Table 5$)$.

When considering the first-line TNFi treatment, risk of uveitis was reduced with ETA versus mAbs but not significantly (RR = $0.97[0.66,1.43], p=0.89)$ and was increased on adjustment for the propensity score but not significantly $(R R=1.10[0.70$; 1.72], $\mathrm{p}=0.68)$ (Table 5).

When considering total TNFi treatment exposure (all prescribed therapeutic lines), risk of uveitis was higher with ETA than mAbs but not significantly ( $R R=1.01[0.61 ; 1.69], p=0.96)$ and was further increased on adjustment for the propensity score but still not significantly $(R R=1.21[0.68,2.16], p=0.53)($ Table 5$)$.

Table 5

Incidence of uveitis with mAb and ETA, without and with adjustment for propensity score (PS)

\begin{tabular}{|llllll|}
\hline & & \multicolumn{4}{ll}{ ETA versus mAb (reference $=$ mAb) } \\
\cline { 2 - 6 } & & \multicolumn{2}{l}{ Qualitative analysis } & \multicolumn{2}{l|}{ Quantitative analysis } \\
\cline { 3 - 6 } & & OR $[95 \% \mathrm{Cl}]$ & $\mathrm{p}$ & $\mathrm{RR}[95 \% \mathrm{Cl}]$ & $\mathrm{p}$ \\
\hline First year of TNF inhibitor treatment & Unadjusted for PS & $0.81[0.32,2.03]$ & 0.65 & $0.54[0.24,1.24]$ & 0.15 \\
\cline { 2 - 6 } & Adjusted for PS & $0.94[0.35,2.54]$ & 0.90 & $0.62[0.26,1.46]$ & 0.27 \\
\hline First-line TNF inhibitor & Unadjusted for PS* & $1.39[0.71,2.72]$ & 0.30 & $0.97[0.66,1.43]$ & 0.89 \\
\cline { 2 - 6 } & Adjusted for PS* & $1.89[0.90,4.01]$ & 0.09 & $1.10[0.70,1.72]$ & 0.68 \\
\hline All therapeutic lines of TNF inhibitors & Unadjusted for PS* & $1.57[0.71,3.46]$ & 0.27 & $1.01[0.61 ; 1.69]$ & 0.96 \\
\cline { 2 - 6 } & Adjusted for PS* & $1.98[0.90,4.37]$ & 0.08 & $1.21[0.68,2.16]$ & 0.53 \\
\hline
\end{tabular}

OR, odds ratio; $\mathrm{RR}$, relative risk; $95 \% \mathrm{Cl}, 95 \%$ confidence interval

* Adjusted for duration of TNF inhibitor treatment

\section{Discussion}

According to the main result of our study, the type of TNFi chosen does not affect the risk of uveitis in the year after the initiation of TNFi treatment for SpA. The comparisons, both qualitative and quantitative analyses of the incidence of uveitis in the year after introducing the TNFi, found a non-significant reduced risk of developing uveitis with soluble-receptor ETA versus $m A b$ treatment. Adjustment for the propensity score tended to reduce the difference that might have favored ETA, which was 
related rather to differences in baseline covariates according to the treatment assigned. Limiting a prescription for ETA in patients with a history of uveitis might erroneously result in an apparently protective effect of ETA.

The lack of significant difference in the occurrence of uveitis ETA and mAbs contrasts with what was demonstrated in two major observational studies, despite very similar conditions to our cohort $(11,12)$. In these two studies, uveitis incidence was higher with ETA than adalimumab or infliximab over 1 or 2 years of treatment with TNFi. These studies did not use propensityscore adjustment, and patients with a history of uveitis were excluded from the Wendling et al. study (12). In our qualitative analysis, the risk of at least one uveitis episode with first-line TNFi and all therapeutic lines was higher with ETA than mAbs but not significantly. The magnitude of the increased risk with ETA (almost twice that for mAbs) was similar to that found in the Swedish Rheumatology Quality Register; the risk of uveitis at 2 years was increased by 1.99-fold with ETA versus infliximab (11). In our quantitative analysis, risk of uveitis did not differ with ETA and mAbs. This result is consistent with studies using quantitative analysis, such as the Braun et al. study, which did not reveal any difference between ETA and infliximab (1).

Our study also suggested that the risk of uveitis is not associated with the treatment used but is associated with the history of the disease and disease activity. This finding is particularly true because the prevalence of uveitis was, according to our study, the main risk factor for uveitis incidence with TNFi treatment $(p<0.001)$ (Table 5$)$. This increased incidence during the first year of treatment should be noted. The introduction of the first anti-TNF agent in PsA and SpA is usually a result of clinical worsening of disease activity, resulting in a high expected incidence of uveitis in the first months after treatment start, as suggested by the higher proportion of de novo uveitis compared to recurrent uveitis on qualitative analysis in the first year of treatment ( $4.71 \%$ and $2.77 \%$, respectively).

The reduction in incidence of uveitis when all therapeutic lines were considered in comparison to the incidence in patients receiving first-line TNFi treatment reveals that most events occur during the first year of treatment. This reinforces our choice to define the main objective of this study with the first year after the introduction of the first TNFi. This is also the period when the risk of missing data is lowest because patients are monitored regularly.

Our study has several limitations. First, it reflects the practices and prescribing habits of a single rheumatology department. The low number of events may also have resulted in lack of power. The data collection in this retrolective study may also have resulted in potential missing data in medical records and therefore lower prevalence and incidence of uveitis, especially in the pre-treatment period, than values usually reported in the literature (1,19-21). A monitoring bias may have contributed to an increase in number of events reported during treatment because patients were more frequently reviewed and questioned when treated. Recovery of missing data by phone calls was hampered by a large number of patients who could not be reached and substantial memory bias in those contacted. Finally, the observational design of the study implied biases related to the prescription of TNFi, such as a channeling bias.

The main strength of this study is that data were collected from current clinical practice. Almost all patients with SpA or PsA who received TNFi agents in our department were recruited. Given that every first prescription of a TNFi in our country can only be given during a hospital visit, our population is highly representative of the target population. Channeling bias was limited by the use of the propensity score. Indeed, it reduced the confounding biases associated with a different distribution of characteristics measured at baseline and results in pseudo-randomization by rebalancing the confounding factors in the compared treatment groups.

Although the mechanisms of action of the soluble-receptor ETA and mAbs are different (22), our results did not allow us to conclude that ETA or mAbs was more effective against the occurrence of uveitis in the first year of TNFi treatment. When considering a longer follow-up period, the risk of uveitis appeared potentially greater in patients receiving ETA than mAbs, although not significantly.

\section{Conclusion}


These results, in addition to those already published on the same topic, suggest that the choice of TNFi should consider the history of extra-articular symptoms, because occurrence of uveitis in patients receiving a TNFi is linked more to the patient's history of uveitis than the prescribed molecule. Also, a systematic preference for an mAb instead of soluble receptor is not justified in most patients but should be considered in high-risk patients with multiple, frequent and/or complicated uveitis episodes.

\section{Abbreviations}

spondyloarthritis

SpA

psoriatic arthritis

PsA

etanercept

ETA

monoclonal antibodies

mAb

TNF-a inhibitors

$\mathrm{TNFi}$

ankylosing spondylitis

AS

Assessment of SpondyloArthritis international Society

ASAS

odds ratio

OR

relative risk

$\mathrm{RR}$

95\% confidence interval

$\mathrm{Cl}$

MD

missing data

SD

standard deviation

IBD

inflammatory bowel disease

SDMARD

synthetic disease-modifying anti-rheumatic drug

\section{Declarations}

Ethics approval and consent to participate : Not applicable

Consent for publication : Not applicable

Availability of data and materials : The datasets used and/or analysed during the current study are available from the corresponding author on reasonable request

Competing interests : Not applicable

Funding:Pfizer provided an unrestricted grant but was never involved in any step of this study such as protocol conception, data collection, statistical analysis, data interpretation or manuscript drafting and revision. 
Authors contributions:

GK : participated in the development of the study protocol, collected the patients data from medical records, performed a part of stistical analysis and was major contributor in writing the manuscrit

$\mathrm{BC}$ : participated in the development of the study protocol and contributed in writing and correcting the manuscript

$\mathrm{JM}$ : participated in the development of the study protocol and contributed in writing and correcting the manuscript

$\mathrm{CL}$ : participated in the development of the study protocol, performed a part of stistical analysis and contributed in writing and correcting the manuscript

All authors read and approved the final manuscript

Acknowledgements : not applicable

Ethics approval and consent to participate : not applicable

Consent for publication : not applicable

Disclosures:GK: NoneBC received honoraria from Abbvie, BMS, Gilead, Jannsen, Lilly, MSD, Novartis, Pfizer, Roche-Chugai, Sanofi, UCBCL received honoraria from Abbvie, Amgen, BMS, Jannsen, Lilly, MSD, Novartis, Pfizer, Roche-Chugai, Sanofi, UCB

\section{References}

1. Braun J, Baraliakos X, Listing J, Sieper J. Decreased incidence of anterior uveitis in patients with ankylosing spondylitis treated with the anti-tumor necrosis factor agents infliximab and etanercept. Arthritis Rheum. août 2005;52(8):2447-51.

2. Stolwijk C, van Tubergen A, Castillo-Ortiz JD, Boonen A. Prevalence of extra-articular manifestations in patients with ankylosing spondylitis: a systematic review and meta-analysis. Ann Rheum Dis. janv 2015;74(1):65-73.

3. Rosenbaum JT. Uveitis in spondyloarthritis including psoriatic arthritis, ankylosing spondylitis, and inflammatory bowel disease. Clin Rheumatol. juin 2015;34(6):999-1002.

4. Hoeksema L, Los LI. Vision-Related Quality of Life in Patients with Inactive HLA-B27-Associated-Spectrum Anterior Uveitis. PloS One. 2016;11(1):e0146956.

5. Schiffman RM, Jacobsen G, Whitcup SM. Visual functioning and general health status in patients with uveitis. Arch Ophthalmol Chic III 1960. juin 2001;119(6):841-9.

6. Miserocchi E, Modorati G, Mosconi P, Colucci A, Bandello F. Quality of life in patients with uveitis on chronic systemic immunosuppressive treatment. Ocul Immunol Inflamm. août 2010;18(4):297-304.

7. Sieper J, Koenig A, Baumgartner S, Wishneski C, Foehl J, Vlahos B, et al. Analysis of uveitis rates across all etanercept ankylosing spondylitis clinical trials. Ann Rheum Dis. 1 janv 2010;69(01):226-9.

8. Rudwaleit M, Rødevand E, Holck P, Vanhoof J, Kron M, Kary S, et al. Adalimumab effectively reduces the rate of anterior uveitis flares in patients with active ankylosing spondylitis: results of a prospective open-label study. Ann Rheum Dis. mai 2009;68(5):696-701.

9. Yazgan S, Celik U, Işık M, Yeşil NK, Baki AE, Şahin H, et al. Effıcacy of golimumab on recurrent uveitis in HLA-B27-positive ankylosing spondylitis. Int Ophthalmol. févr 2017;37(1):139-45.

10. Rudwaleit M, Rosenbaum JT, Landewé R, Marzo-Ortega H, Sieper J, van der Heijde D, et al. Observed Incidence of Uveitis Following Certolizumab Pegol Treatment in Patients With Axial Spondyloarthritis. Arthritis Care Res. juin 2016;68(6):838-44.

11. Lie E, Lindström U, Zverkova-Sandström T, Olsen IC, Forsblad-d'Elia H, Askling J, et al. Tumour necrosis factor inhibitor treatment and occurrence of anterior uveitis in ankylosing spondylitis: results from the Swedish biologics register. Ann

Page 12/14 
Rheum Dis. 2 mars 2017;

12. Wendling D, Joshi A, Reilly P, Jalundhwala YJ, Mittal M, Bao Y. Comparing the risk of developing uveitis in patients initiating anti-tumor necrosis factor therapy for ankylosing spondylitis: an analysis of a large US claims database. Curr Med Res Opin. déc 2014;30(12):2515-21.

13. Heijde D van der, Ramiro S, Landewé R, Baraliakos X, Bosch FV den, Sepriano A, et al. 2016 update of the ASAS-EULAR management recommendations for axial spondyloarthritis. Ann Rheum Dis. 13 janv 2017; annrheumdis-2016-210770.

14. Rudwaleit M, van der Heijde D, Landewé R, Listing J, Akkoc N, Brandt J, et al. The development of Assessment of SpondyloArthritis international Society classification criteria for axial spondyloarthritis (part II): validation and final selection. Ann Rheum Dis. juin 2009;68(6):777-83.

15. van der Linden S, Valkenburg HA, Cats A. Evaluation of diagnostic criteria for ankylosing spondylitis. A proposal for modification of the New York criteria. Arthritis Rheum. avr 1984;27(4):361-8.

16. Taylor WJ, Robinson PC. Classification criteria: peripheral spondyloarthropathy and psoriatic arthritis. Curr Rheumatol Rep. avr 2013;15(4):317.

17. Austin PC. An Introduction to Propensity Score Methods for Reducing the Effects of Confounding in Observational Studies. Multivar Behav Res. mai 2011;46(3):399-424.

18. Williamson E, Morley R, Lucas A, Carpenter J. Propensity scores: from naive enthusiasm to intuitive understanding. Stat Methods Med Res. juin 2012;21(3):273-93.

19. Brandt J, Khariouzov A, Listing J, Haibel H, Sörensen H, Grassnickel L, et al. Six-month results of a double-blind, placebocontrolled trial of etanercept treatment in patients with active ankylosing spondylitis. Arthritis Rheum. juin 2003;48(6):1667-75.

20. Braun J, Brandt J, Listing J, Zink A, Alten R, Golder W, et al. Treatment of active ankylosing spondylitis with infliximab: a randomised controlled multicentre trial. Lancet Lond Engl. 6 avr 2002;359(9313):1187-93.

21. Brandt J, Listing J, Haibel H, Sörensen H, Schwebig A, Rudwaleit M, et al. Long-term efficacy and safety of etanercept after readministration in patients with active ankylosing spondylitis. Rheumatol Oxf Engl. mars 2005;44(3):342-8.

22. Savion S, Oddo S, Grover S, Caspi RR. Uveitogenic T lymphocytes in the rat: pathogenicity vs. lymphokine production, adhesion molecules and surface antigen expression. J Neuroimmunol. nov 1994;55(1):35-44.

\section{Figures}




\section{Diagnosis $\quad$ First administration of TNF-inhibitor}

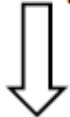
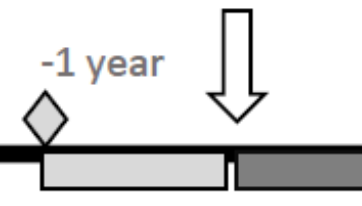

+1 year

Figure 1.a: The last year before and first year after initiating the first-line TNF inhibitor

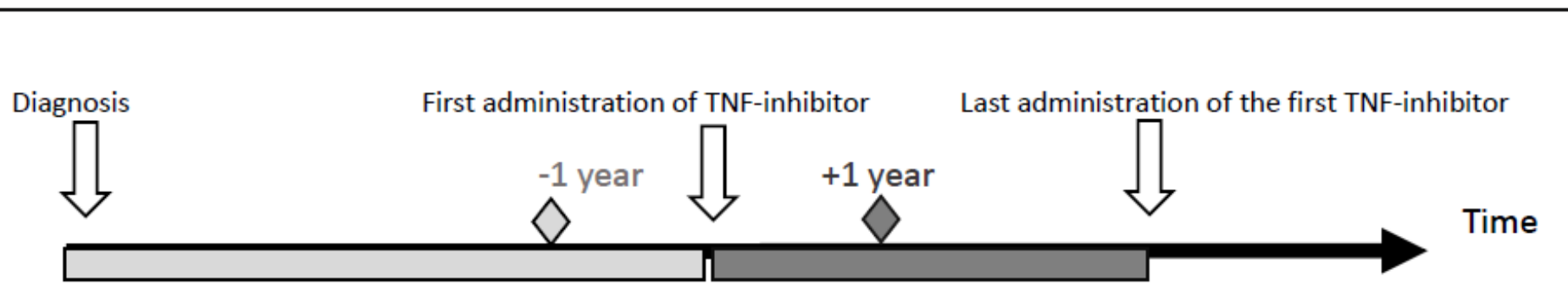

Figure 1.b: The pre-treatment and first-line TNF inhibitor treatment periods

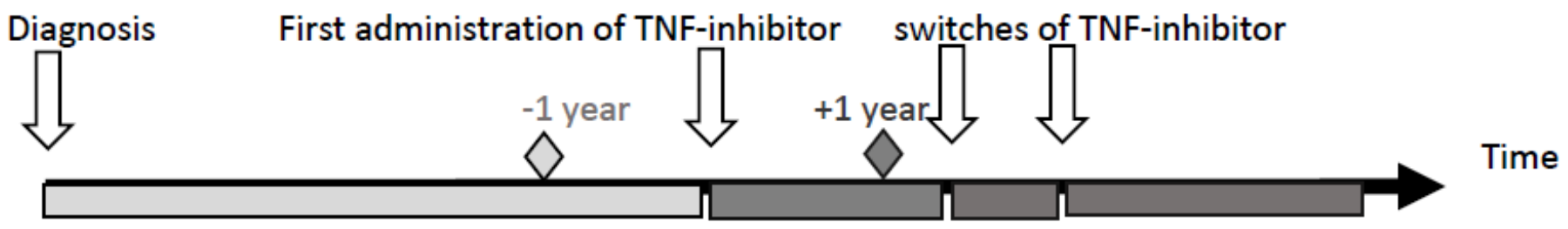

Figure 1.c: The pre-treatment and all therapeutic lines of TNF inhibitor treatments periods

Figure 1

The time intervals involved in the statistical analyses

\section{Supplementary Files}

This is a list of supplementary files associated with this preprint. Click to download.

- SupplementaryfigureS1.pdf

- Supplementaryfigures2.pdf

- SupplementarytableS1.docx 